\title{
Radon Risks Assessment with the Covid-19 Lockdown Effects
}

\section{Josue Maya 1,2, Lawan Loubou Mohamadou1,3, Serge Mbida Mbembe ${ }^{1,4}$, André Atangana Likéné1,5, Bertrand Akamba Mbembe1,4, Maimounatou Boubakari1,5}

${ }^{1}$ National Radiation Protection Agency, Yaoundé, Cameroon

${ }^{2}$ Department of Physics, Faculty of Science, University of Ngaoundere, Ngaoundere, Cameroon

${ }^{3}$ Faculty of Health Sciences, University of Buea, Buea, Cameroon

${ }^{4}$ Laboratory of Nuclear Physics, Department of Physics, Faculty of Science, University of Yaounde I, Yaounde, Cameroon

${ }^{5}$ Centre for Atomic Molecular Physics and Quantum Optics, University of Douala, Douala, Cameroon

Email: mayajosue@gmail.com

How to cite this paper: Maya, J., Mohamadou, L.L., Mbembe, S.M., Likéné, A.A., Mbembe, B.A. and Boubakari, M. (2020) Radon Risks Assessment with the Covid-19 Lockdown Effects. Journal of Applied Mathematics and Physics, 8, 1402-1412. https://doi.org/10.4236/jamp.2020.87106

Received: July 2, 2020

Accepted: July 25, 2020

Published: July 28, 2020

Copyright (c) 2020 by author(s) and Scientific Research Publishing Inc. This work is licensed under the Creative Commons Attribution International License (CC BY 4.0)

http://creativecommons.org/licenses/by/4.0/

\section{Open Access}

\begin{abstract}
This work draws attention to the effects of the second cause of lung cancer which is also the largest source of exposure to ionizing radiation, radon, during the lockdown recommended by the World Health Organization (WHO) due to the Covid-19 pandemic. The basic assumption is that the exposure times have been assimilated to the 03-month lockdown time and the 02-week maximum incubation period of the disease. Doses during these periods and Relative Risk of Lung Cancer (RRLC), Lung Cancer Cases per year per million people (LCC) and Excess Lifetime Risk of Cancer (ELRC), were evaluated based on the concentrations obtained in high natural background radiation area in Cameroon. The existing exposure situation due to radon is then reevaluated and ranged from $0.76 \%$ to $17.55 \%$. These results show that the reconsidered exposure time would be equivalent to the exposure time of a worker over one year, with their respective doses values becoming equivalent. The risks of developing lung cancer were also evaluated and it has been found that due to this pandemic it unfortunately increased.
\end{abstract}

\section{Keywords}

Radon, Lockdown, Lung Cancer, Doses, Risks

\section{Introduction}

The advent of Covid-19 has changed the behaviors and lifestyles of the entire population of the planet. The World Health Organization (WHO) on the battlefront against Covid-19, the International Labor Organization (ILO), the Interna- 
tional Atomic Energy Agency (IAEA) and the whole of the world scientific community are working on how to stop the disease spreading and are making their contribution to mitigating the consequences, which are being felt on the health, economic and social levels. Due to this pandemic, there is for instance the use of CT scan and X-ray in the rapid diagnosis of advanced cases of Covid-19 [1] [2].

The conditions imposed by the Covid-19 such as lockdown recommended by WHO to limit the spread of Covid-19, increased the residence time of families and workers inside their homes. This would have the direct consequence by increasing exposure to radioactive gases such as radon 222, also increasing the health risks due to its inhalation [3]. In addition to air quality, tobacco consumption can also contribute to the rise of lung diseases and especially lung cancer [4].

Lockdown as a measure to limit the spread of Covid-19 forces people sometimes to breathe poor air quality that does not meet environmental criteria. If the air quality of gaseous and particulate pollutants is improved during the lockdown [5] [6] [7], radon exposure, which is the largest contributor to natural exposure to ionizing radiation and the second leading cause of lung cancer in confined spaces, may influence the risk of developing these diseases.

Radon $\left({ }^{222} \mathrm{Rn}\right)$ is a naturally occurring radioactive gas, which is inert, colorless, and odorless. It is generated primarily from radium $\left({ }^{226} \mathrm{Ra}\right)$, which results from the radioactive decay of uranium $\left({ }^{238} \mathrm{U}\right)$. Radon disintegrates into a series of short-lived alpha-emitting daughter radionuclides, such as ${ }^{218} \mathrm{Po},{ }^{214} \mathrm{~Pb},{ }^{214} \mathrm{Bi}$, and ${ }^{214} \mathrm{Po}$. In non-smokers, radon is the primary cause of lung cancer. Radon occurrence in the environment is mainly related to the high-level radioactive background. Its global average outdoor level ranges between $5-15 \mathrm{~Bq} / \mathrm{m}^{3}$ meanwhile the annual worldwide average radiation dose from exposure due to naturally occurring radiation sources, including radon, is $2.4 \mathrm{mSv}$ [8]. The radon air concentration varies between $100 \mathrm{~Bq} / \mathrm{m}^{3}$ and $300 \mathrm{~Bq} / \mathrm{m}^{3}$ as recommended respectively by the WHO [9] and ICRP [10].

In Cameroon, several studies have been carried out to measure concentration of radon in dwelling. Many radon measurement campaigns in dwellings have been led across the country. They consisted to deposit nuclear solid state track detectors of radon (E-Perm Electret, Raduet, Radtrack) in the dwellings of different localities of Cameroon. These devices were hung for at least 3 months in dwellings.

The indoor radon, concentration was measured in 103 and 50 dwellings located respectively in Poli and Lolodorf with respective means concentration of $294 \mathrm{~Bq} / \mathrm{m}^{3}$ and $687 \mathrm{~Bq} / \mathrm{m}^{3}$. For the both region, $80 \%$ of dwellings have radon concentration above the reference level of $100 \mathrm{~Bq} / \mathrm{m}^{3}$. In Lolodorf, $50 \%$ of dwellings showed a radon concentration above $300 \mathrm{~Bq} / \mathrm{m}^{3}$ meanwhile in Poli it is $20 \%$ and $60 \%$ in the Bakassi oil-bearing peninsula [11]. Indoor radon concentrations in 15 dwellings of the Bakassi Peninsula present an average value of $1280 \mathrm{~Bq} / \mathrm{m}^{3}$. $60 \%$ of dwellings have an indoor radon concentration above the reference level 
of $300 \mathrm{~Bq} / \mathrm{m}^{3}$. An inhalation dose of $29.3 \mathrm{mSv} / \mathrm{y}$ was calculated [10]. The Arithmetic mean radon concentrations in 71 dwellings of Douala City were estimated to be $139 \mathrm{~Bq} / \mathrm{m}^{3}$ [12]. Indoor radon $(\mathrm{Rn})$ concentration means measured in the gold mining areas of Betare-Oya using RADUET detectors and TnP monitors were $133 \pm 39 \mathrm{~Bq} / \mathrm{m}^{3}$. The $76 \%$ of houses for Rn exceed the WHO reference level of $100 \mathrm{~Bq} / \mathrm{m}^{3}$ and $3 \%$ of the houses exceed the ICRP threshold of $300 \mathrm{~Bq} / \mathrm{m}^{3}$ [13]. It is important to note that these results were obtained in the dwellings of Cameroon during normal periods before the advent of the Covid-19 pandemic. It should be noted that the risk of lung cancer based on the results obtained in certain localities can be evaluated differently and compared with recent statistics.

Therefore, we purpose in this study to conduct a risk assessment exposure to radon as a public health problem based on the available concentration measure in the high-level background radioactive areas in Cameroon during the lockdown caused by Covid-19.

\section{Methods}

\subsection{Exposure Times, Occupation and Equilibrium Factors}

Working hours or exposure periods for workers have varied over the years, as mentioned by the International Labor Organization. It reports that, the Covid-19 pandemic is having catastrophic effects on working hours while the WHO calls the world's population to stay at home. According to the ICRP 93 [14], one is supposed to spend 7000 hours/year at home and 2000 hours/year at work. Thus, like several authors who have calculated the doses over a year, i.e. 7830 hours [15]; we can adapt ours to the prevailing situation. This is what Krstić [16] notes when he suggests the need to re-evaluate the accounting of lung cancer attribution estimates for various behavioral, lifestyle, occupational, environmental, biological an and socioeconomic risk factors. Our approach will consist in evaluating the risk of lung cancer due to Radon 222 in people confined to households during the lockdown period and compare this same risk of lung cancer during the normal period without pandemic in Covid-19.

As recommended by WHO, lockdown has been applied in Cameroon as a means of fighting the pandemic. From the declaration of the first cases to the resumption of classes, we have about 03 months which can be assumed to be the time of exposure to radon or the time of lockdown observed especially as the instructions to stay at home was declared. It should be noted that in radiation protection, calculations are made by taking the most unfavorable cases to optimize protection.

Therefore the exposure time for a person in lockdown will be:

Texp $1=3$ months $\times 4$ weeks $\times 7$ days $\times 24$ hours $=2160$ hours.

For a person confined for 14 days, which is the maximum incubation period of the virus, the exposure time would be:

$$
\text { Texp2 = } 14 \text { days } \times 24 \text { hours }=336 \text { hours. }
$$


Thus, radon doses and risks will be re-evaluated based on these periods.

As the equilibrium factor depends on on-air exchange, the lockdown influence the way of life, most precisely ventilation in the home, especially in tight constructions and small houses. The occupancy factor with the instructions to stay at home can reach $100 \%$. It is difficult to measure it in practice as it widely varied with age, occupation, state of health, climate and is usually higher in cold climate countries [17]. The default equilibrium factor is 0.4 and can vary from 0.2 to $0.7[18]$.

\subsection{Area of Study}

Cameroon's mining potential [19] presents high natural background radiation areas that have been subjected to radon measurements. In order to cover the entire nation, some localities in 05 regions was concerned, in particular the locality of Poli in the North [11], those of Lolodorf, Bikoue, and Ngombas in the South [20], Bakassi in the South-West region [21], Betaré-Oya in the East [22] and the city of Douala, capital of the Littoral region [12]. To values obtained in these localities, we associate some limits concentrations of international institutions for comparison.

\subsection{Evaluation of the Annual Effective Dose (AED), Effective Dose to Lung (EDL), Excess Lifetime Cancer Risk (ELCR) Lung Cancer Case (LCC), and Relative Risk Lung Cancer (RRLC)}

Doses from inhaled radon $\left(\mathrm{E}_{\text {inh }}(\mathrm{Rn})\right)$ were calculated according to the following equation [Unscear 2000]:

$$
\mathrm{E}_{\mathrm{inh}}(\mathrm{Rn})=\left(\mathrm{CRn} \times \mathrm{e}_{\mathrm{inh}}(\mathrm{Rn}) \times \mathrm{Feq}\right) \times \text { Focc }_{i=1-3} \times T
$$

$\mathrm{CRn}$ is the radon concentrations whereas $\mathrm{e}_{\mathrm{inh}}(\mathrm{Rn})\left(9 \mathrm{nSv}\left(\mathrm{Bq} \cdot \mathrm{h} \cdot \mathrm{m}^{-3}\right)^{-1}\right)$, Feq (0.4), Focc $_{i=1-3}=\{0.6,0.8,1)$ and $T(02$ weeks and 03 months) represent respectively the radon dose factors, the equilibrium factors which is the ratio between the concentration of radon progeny and radon-222, the occupancy factors of the study area and the exposure time.

The annual effective dose to the lungs will be calculated as follows:

$$
\mathrm{EDL}=\mathrm{E}_{\text {inh }}(\mathrm{Rn}) \times W_{R} \times W_{T}
$$

The radiation-weighting factor $W_{T}$ is 20 for alpha particles and $W_{T}$ is the tissue weighting factor ( 0.12 for lungs).

The excess lifetime cancer risk (ELCR) was calculated using the following formula [23]:

$$
\mathrm{ELCR}=\mathrm{E}_{\text {inh }}(\mathrm{Rn}) \times \mathrm{DL} \times \mathrm{RF}
$$

where DL is the estimated average lifetime of 60 years in Cameroon and RF is the risk of fatal cancer per Sievert $\left(5.5 \times 10^{-2} \mathrm{~Sv}^{-1}\right)$ [24].

The number of Lung Cancer Cases per year per million people (LCC) is given by the equation below: 


$$
\mathrm{LCC}=\mathrm{E}_{\text {inh }}(\mathrm{Rn}) \times 18 \times 10^{-6}
$$

The relative risk of lung cancer (RRLC) due to indoor exposure to radon was calculated using the following equation [25]:

$$
\text { RRLC }=\exp (0.00087352 \mathrm{CRn})
$$

\section{Results and Discussion}

Table 1 presents results computed values of annual effective dose due to inhalation of ${ }^{222} \mathrm{Rn}$, effective dose to lung, relative risk of lung cancer, lung cancer cases per year par million person, and the excess lifetime cancer risk for an exposure time of $7000 \mathrm{~h} / \mathrm{y}$. The evaluation of the radiological risk due to Radon during the lockdown period was estimated in the population of Cameroon through parameters such as exposure time and occupation factors.

\subsection{Radon Activity Concentration}

The available values of indoor radon concentration reported in Table 1 except in Bakassi $\left(1280 \mathrm{~Bq} / \mathrm{m}^{3}\right)$ are in the range of the radon action level $(200-600) \mathrm{Bq} / \mathrm{m}^{3}$ as recommended by ICRP-1993, higher than the WHO reference level of 100 $\mathrm{Bq} / \mathrm{m}^{3}$ and the action level $\left(148 \mathrm{~Bq} / \mathrm{m}^{3}\right)$ of the Environmental Protection Agency (EPA). Those high concentrations were expected as the areas of study are high background radioactivity [26] [27]. Such high values found in High Natural Background Radiation Areas (HNBRA), must be confirmed to be the most consistent measurement. In fact, the number of dosimeters and dwellings can be increased in order to cover systematically all HNBRA in the country. Short-term and continuous measurements can help be carried out for more accuracy. We can notice that the few measurements done using EICs detector give high values than those obtained from Raduet detectors. Attention can be paid in the choice

\begin{tabular}{|c|c|c|c|c|c|c|c|}
\hline $\mathrm{N}^{\bullet} 1$ & Localities/Countries & $\mathrm{CRn}\left(\mathrm{Bq} / \mathrm{m}^{3}\right)$ & Inhalation Dose (mSv) & RRLC (\%) & Dose to lung (mSv/y) & $\operatorname{LLC} \times 10^{-6}$ & ELCR \\
\hline 1 & Poli (EICs) & 294 & 5.93 & 1.29 & 14.22 & 106.69 & $1.96 \mathrm{E}-02$ \\
\hline 2 & Lolodorf (EICs) & 687 & 13.85 & 1.82 & 33.24 & 249.30 & $4.57 \mathrm{E}-02$ \\
\hline 3 & Lolodorf (RADUET) & 92 & 1.85 & 1.08 & 4.45 & 33.38 & $6.12 \mathrm{E}-03$ \\
\hline 4 & Bakassi (EICs) & 1280.0 & 25.80 & 3.06 & 61.93 & 464.49 & $8.52 \mathrm{E}-02$ \\
\hline 5 & Douala (RADUET) & 139 & 2.80 & 1.13 & 6.73 & 50.44 & $9.25 \mathrm{E}-03$ \\
\hline 6 & Betaré-Oya (RADUET) & 133 & 2.68 & 1.12 & 6.44 & 48.26 & $8.85 \mathrm{E}-03$ \\
\hline 9 & EPA (US) & 148 & 2.98 & 1.14 & 7.16 & 53.71 & $9.85 \mathrm{E}-03$ \\
\hline 10 & WHO & 100 & 2.02 & 1.09 & 4.84 & 36.29 & $6.65 \mathrm{E}-03$ \\
\hline \multirow[t]{4}{*}{11} & ICRP & 300 & 6.05 & 1.30 & 14.52 & 108.86 & $2.00 \mathrm{E}-02$ \\
\hline & Min (Cameroon) & 92.00 & 1.85 & 1.08 & 4.45 & 33.38 & $6.12 \mathrm{E}-03$ \\
\hline & Max (Cameroon) & 1280 & 25.80 & 3.06 & 61.93 & 464.49 & $8.52 \mathrm{E}-02$ \\
\hline & Average (Cameroon) & 437.50 & 8.82 & 1.59 & 21.17 & 158.76 & $2.91 \mathrm{E}-02$ \\
\hline
\end{tabular}

Table 1. Evaluation of AEF, EDL, RRLC, LLC, and ELCR with exposure time of $7000 \mathrm{~h} / \mathrm{y}$. 
of the type of detector that can be used in the future. Further measurements are being carried out so that a radon mapping, a categorization of areas and the reference level can be established the regulatory body. IAEA requires that the regulatory body or other relevant authority such as a health authority assigned to establish a protection strategy for an existing exposure situation shall ensure that, it specifies appropriate reference since remedial actions shall be undertaken [28].

\subsection{Annual Effective Dose and Annual Effective Dose to Lung}

According to Table 1, the values of annual effective doses for radon inhalation by the inhabitants were found between 0.85 (Lolodorf) to $25.80 \mathrm{mSv} / \mathrm{y}$, (Bakassi) with a mean of $8.84 \mathrm{mSv} / \mathrm{y}$. It can be observed that, doses shown annual effective dose within the ICRP recommended action level of $3-10 \mathrm{mSv} / \mathrm{y}$ even as the maximum value is above. The annual effective dose to lung range from 4.45 to $61.93 \mathrm{mSv} / \mathrm{y}$ with an average of $21.17 \mathrm{mSv} / \mathrm{y}$. Compared to doses calculated using the concentration limits of EPA, ICRP, and IAEA, these values are quite high and should be considered cautiously as the measurement points are not significant to conclude.

\subsection{Lung Cancer Cases}

The lung cancer cases per year per million person (LLC) goes from 33.38 to 464.49 per million persons per year. The LLC average of 158.76 per million persons per year is in the limit range between 170 and 230 per million persons recommended by ICRP [14]. According to the Global Cancer Observatory (GLOBOCAN) in 2018, with a total population of 24,678,233 in Cameroon, there are 15,769 new cancer cases, 10,533 deaths, and 27,048 prevalent cases (5-year). A part from breast $(20.8 \%)$, cervix uteri $(14.9 \%)$, prostate $(14 \%)$, liver $(6.1 \%)$, and colorectum (5.5\%) cancers other types represent 38.7\% (6101) including the lung cancer. Moreover, lung cancer deaths in Cameroon reached 198 i.e. 0.09\% of total deaths from the WHO data of 2018. Based on the fact that the LCC is 158.76, out of the total population there will be 3918 cases of lung cancer out of the 6101 other types of cancers, i.e. $24.85 \%$ which is about the percentage of breast cancer (20.8\%). Besides, even the press release $n^{\circ} 263$ of the International Agency for Research on Cancer reported that the cancers of the lung and female breast are the leading types worldwide in terms of the number of new cases; for each of these types, approximately 2.1 million diagnoses are estimated in 2018.

\subsection{Excess Lifetime Cancer Risk}

The ELCR was found varying from $0.061 \times 10^{-2}$ to $8.52 \times 10^{-2}$. The average of $2.91 \times 10^{-2}$ compared to the world average $\left(0.29 \times 10^{-3}\right.$ for a world permissible annual effective dose equivalent of $70 \mu \mathrm{Sv} / \mathrm{y}$ [8]) is 100 times greater but the fact that measurement was made high natural radioactive areas and their few numbers can reduce this ratio. 
A simple reconsideration of exposure of times from a year to 03 months makes that in lockdown period, someone can receive doses equal to the UNSCEAR Worker exposure.

\subsection{Lockdown Effects on Doses and Risks}

Based on the assumption made in Section 2, the doses and risks presented above have been reassessed and plotted in Figures 1(a)-(h). The AED in 03 months and 02 weeks ranged from 0.43 to $9.95 \mathrm{mSv}$ and from 0.07 to $1.55 \mathrm{mSv}$, respectively. The EDL is in the range of $1.03-23.89 \mathrm{mSv}$ (03 months) and $0.16-3.72$ $\mathrm{mSv}$ (02 weeks). The ELCR ranges from 0.99 - 23.03 in 03 months of exposure and $0.15-3.58$ for 02 weeks. For 03 months and 02 weeks, the LCC is in the range of $7.73-179.16$ and $1.20 \%-27.87 \%$.

Even if it is obvious that the lockdown has effects on radon exposure through exposure time or occupancy factor, quantifying it in percentage terms help to more appreciate it. For example, if we consider the exposure time of 03 months

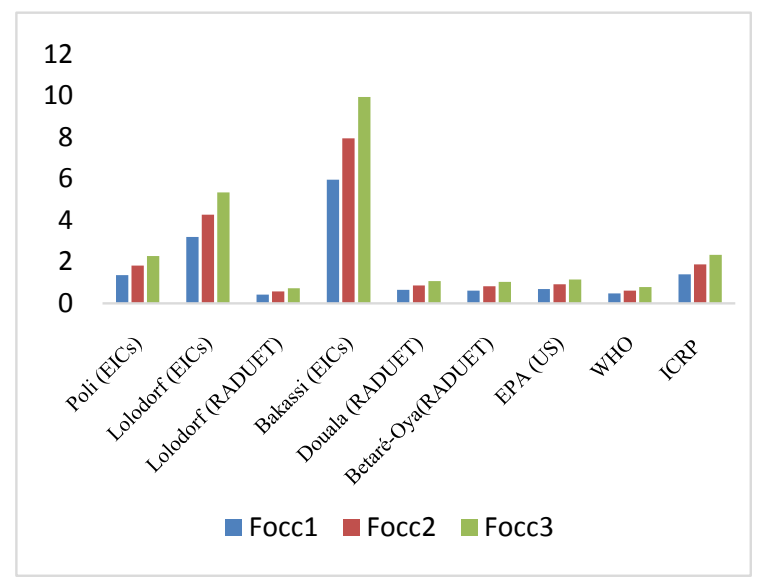

(a)

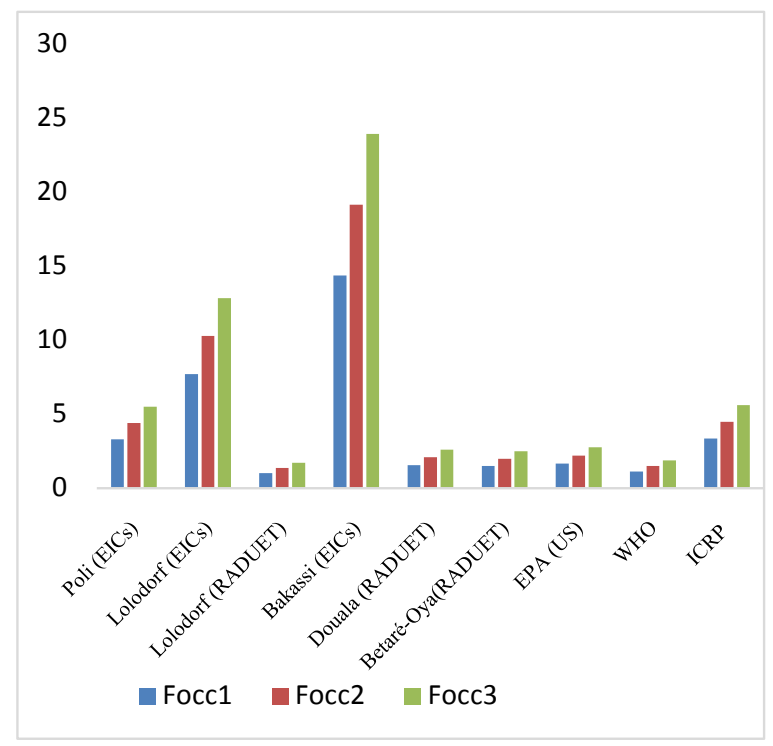

(c)

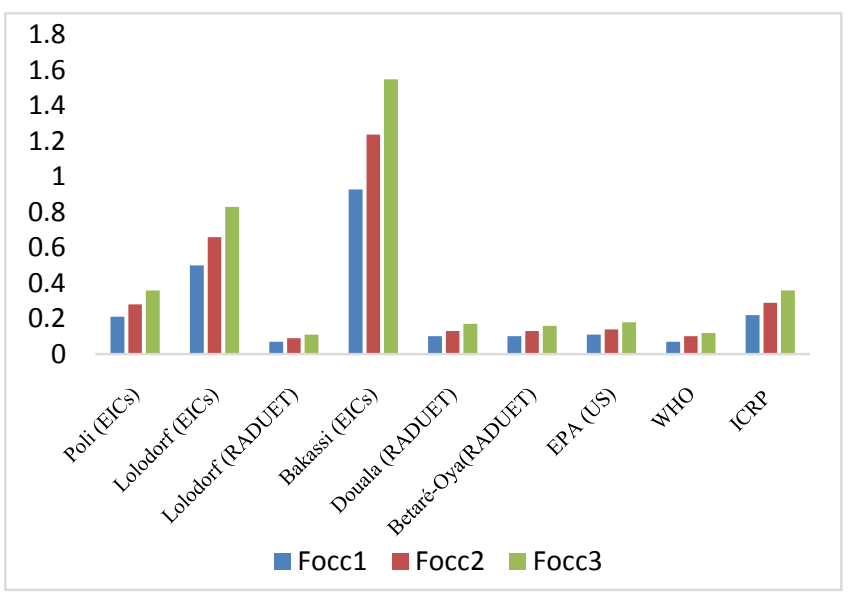

(b)

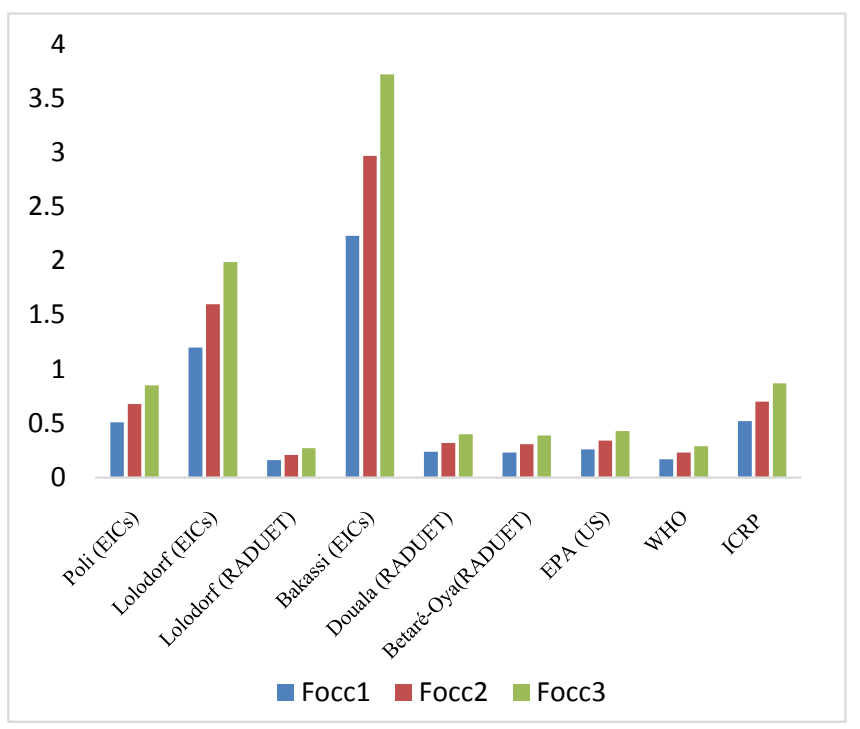

(d) 


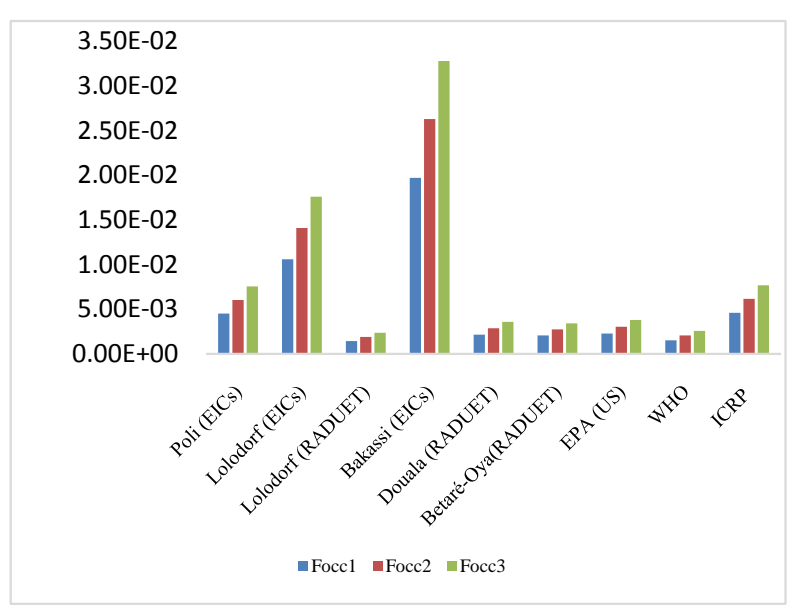

(e)

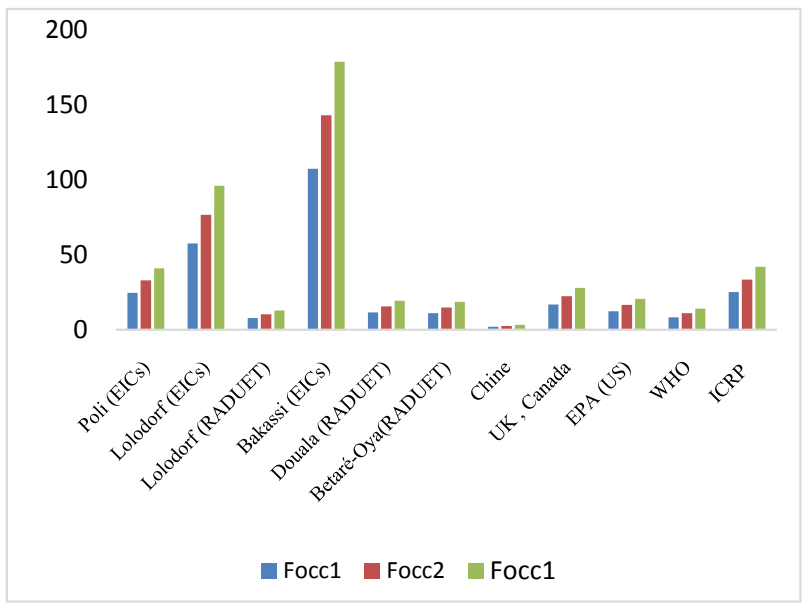

(g)

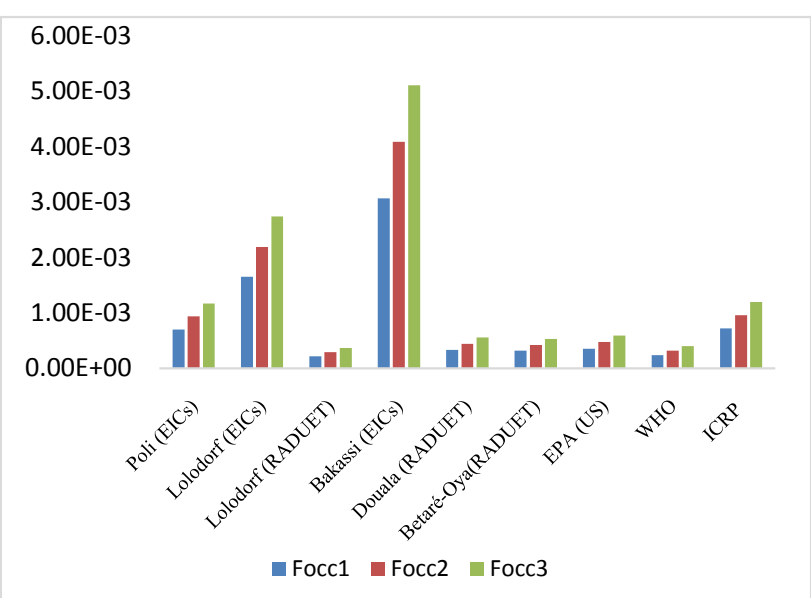

(f)

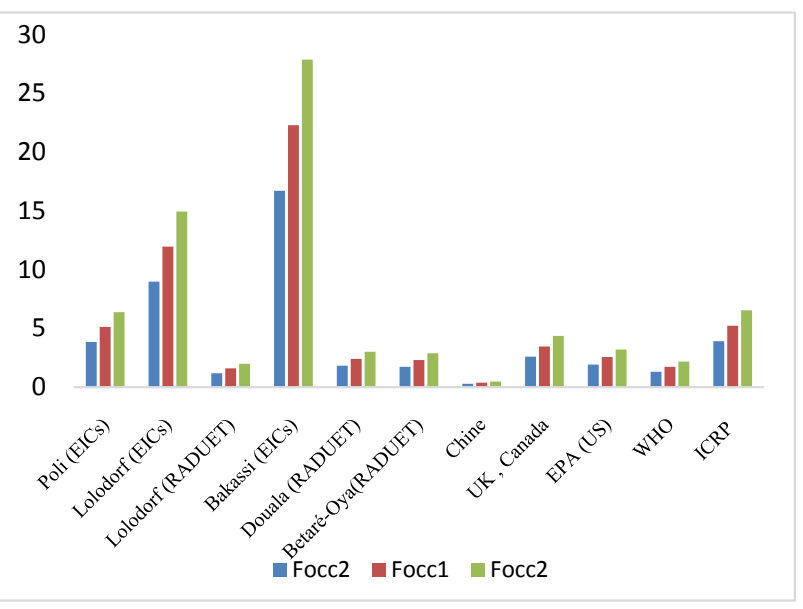

(h)

Figure 1. (a) Effective doses (mSv/y) through inhalation in lockdown of 03 months; (b) Effective doses (mSv/y) through inhalation in 02 weeks; (c) Annual effective dose (AED) (mSv/y) to lungs in lockdown of 03 months; (d) Annual effective dose (AED) $(\mathrm{mSv} / \mathrm{y})$ to lungs in lockdown of 02 weeks; (e) Excess lifetime cancer risk (ELCR) in lockdown of 03 months; (f) Excess lifetime cancer risk (ELCR) in lockdown of 02 weeks; (g) Lung cancer cases per year per million person (LCC) in lockdown of 03 months; (h) Lung cancer cases per year per million person (LCC) in lockdown of 2 weeks.

and 02 weeks, this amounts to receiving respectively $4.80 \%$ and $30.86 \%$ of annual dose over $7000 \mathrm{~h} / \mathrm{y}$ during these periods. For all the evaluated quantities (Annual Effective Dose, Equivalent Dose to lung, Excess lifetime Cancer Risk, Relative Risk of Lung Cancer and Lung Cancer Cases per million person), with an occupancy factor varying from 0.6 to 1 and lockdown time of 03 months, we can expect a ratio of $4.87 \%$ to $112.85 \%$ of the value received in $7000 \mathrm{~h} / \mathrm{y}$ of exposure. In a two-week quarantine, it range from $0.76 \%$ to $17.55 \%$. The equilibrium factor could also be taken into account in this kind of approach but since it is more a natural decay process between radon and these progenies than human intervention, we choose not to vary it in our assessment.

\section{Conclusion}

The disturbances caused by Covid-19 are felt at several levels of human health. 
Through this study, which aimed at estimating the effects of lockdown time on the inhaled doses of radon on humans and the associated cancer risk, we have demonstrated that the doses that will be received this year may increase from $0.76 \%$ to $17.55 \%$. The dose from exposure to radon by ingestion through drinking water can also be taken into account to improve this type of study. Exposure time ( $8760 \mathrm{hr} / \mathrm{y}, 7000 \mathrm{hr} / \mathrm{y}$ and $2000 \mathrm{~h} / \mathrm{y})$ and occupancy factors can be adapted on a case-by-case basis for a more accurate assessment of indoor and outdoor exposures to re-estimate ambient doses received in the High Natural Background Radioactive Area. Ventilation and flooring retrofitting instructions against radon/thoron soil emissions are highly recommended and the attention given to the reading of this scientific essay contributes to the enrichment of the reader's safety culture. While any scientific study comes with its share of uncertainty and parameter approximation, it is nonetheless true that lockdown would influence radon exposure and associated risks.

\section{Conflicts of Interest}

The authors declare no conflicts of interest regarding the publication of this paper.

\section{References}

[1] Parry, A.H. and Wani, A.H. (2019) Segmental Pulmonary Vascular Changes in COVID-19, Pneumonia. American Journal of Roentgenology, W1. https://doi.org/10.2214/AJR.20.23443

[2] Ye, Z., Zhang, Y. and Wang, Y. (2020) Chest CT Manifestations of New Coronavirus Disease 2019 (COVID-19): A Pictorial Review. European Radiology, 30, 4381-4389. https://doi.org/10.1007/s00330-020-06801-0

[3] Namendys-Silva, S.A. (2020) Respiratory Support for Patients with COVID-19 Infection. The Lancet Respiratory Medicine, 8, 18. https://doi.org/10.1016/S2213-2600(20)30110-7

[4] Berlin, I., Thomas, D., Le Faou, A.-L. and Cornuz, J. (2020) COVID-19 and Smoking. Nicotine \& Tobacco Research, ntaa059.

[5] Nakada, L.Y.K. and Urban, R.C. (2020) COVID-19 Pandemic: Impacts on the Air Quality during the Partial Lockdown in São Paulo State, Brazil. Science of the Total Environment, 730, Article ID: 139087. https://doi.org/10.1016/j.scitotenv.2020.139087

[6] Mahato, S., Pal, S. and Gopal Ghosh, K. (2020) Effect of Lockdown amid COVID-19 Pandemic on Air Quality of the Megacity Delhi, India. Science of the Total Environment, 730, Article ID: 139086. https://doi.org/10.1016/j.scitotenv.2020.139086

[7] Shrestha, A.M., Shrestha, U.B., Sharma, R., Bhattarai, S., Tran, H.N.T. and Rupakheti, M. (2020) Lockdown Caused by COVID-19 Pandemic Reduces Air Pollution in Cities Worldwide. https://doi.org/10.31223/osf.io/edt4j

[8] United Nations Scientific Committee on the Effect of Atomic Radiation Sources (1988) Effects and Risks of Ionising Radiation Report to the General Assembly with Annexes. United States Publication E88ix 17, United Nations, New York.

[9] WHO World Health Organization (2009) Handbook on Indoor Radon: A Public Health Perspective. WHO Library Cataloguing-in-Publication Data. Geneva. 
[10] ICRP (2011) Radiological Protection against Radon Exposure. Draft Report for Consultation. Pergamon Press, Oxford.

[11] Abdourahimi, S., Tchuente Siaka, Y.F. and Bouba, O. (2014) Indoor Radon Measurements in the Uranium Regions of Poli and Lolodorf, Cameroon. Journal of Environmental Radioactivity, 136, 36-40. https://doi.org/10.1016/j.jenvrad.2014.05.001

[12] Takoukam, S.D., Saïdou, S., Tokonami, S., Hosoda, M., Suzuki, T., Kudo, H. and Bouba, O. (2019) Simultaneous Measurements of Indoor Radon and Thoron and Inhalation Dose Assessment in Douala City, Cameroon. Isotopes in Environmental and Health Studies, 55, 499-510.

[13] Saïdou, S., Tokonami, M., Hosoda, Y.F., et al. (2019) Natural Radiation Exposure to the Public in the Uranium Bearing Region of Poli, Cameroon: From Radioactivity Measurements to External and Inhalation Dose Assessment. Journal of Geochimical Exploration, 55, 499-510. https://doi.org/10.1016/j.gexplo.2019.106350

[14] ICRP (1993) Protection against Radon-222 at Home and Works (International Commission on Radiological Protection). ICRP Publication, 65.

[15] Traore, I., Nachab, A., Bâ, A., Nourreddine, A. and Togo, V. (2013) Assessment of Activity and Effective Dose Rate of $222 \mathrm{RN}$ in Several Dwellings in Bamako. Radioprotection, 48, 277-284. https://doi.org/10.1051/radiopro/2012050

[16] Krsti, G. (2016) Radon vs. Other Lung Cancer Risk Factors: How Accurate Are the Attribution Estimate. Journal of the Air \& Waste Management Association, 67, 261-266.

[17] Report No. 15 Radon in Indoor Air (1995) Environment and Quality of Life. European Collaborative Action Door Air Quality \& Its Impact on Man (Formerly COST Project 613).

[18] Melloni, B., Vergnenègre, A., Lagrange, P. and Bonnaud, F. (2000) Prise en charge des cancers bronchiques en Ile-de-France. Revue des Maladies Respiratoires, 17, 1061.

[19] Manyacka, E. and Nguepjouo, D. (2008) Etat des lieux des activités d'exploration de l'uranium dans la partie septentrionale du Cameroun Cas du permis de recherche de Poli dans le département du Faro. Centre pour l'Environnement et le Développement (CED) Report.

[20] Saïdou, Tokonami, S., Bineng, G.S., Abdourahimi and Ndjana Nkoulou, J.E. (2015) Radon-Thoron Discriminative Measurements in the High Natural Radiation Areas of Southwestern Cameroon. Journal of Environmental Radioactivity, 150, 242-246. https://doi.org/10.1016/j.jenvrad.2015.09.006

[21] Saïdou, A., TchuenteSiaka, Y.F. and KwatoNjock, M.G. (2015) Natural Radiation Exposure to the Public in the Oil-Bearing Bakassi Peninsula, Cameroon. Radioprotection, 50, 35-41. https://doi.org/10.1051/radiopro/2014025

[22] NdjanaNkoulou II, J.E., NgoaEngola, L., Saïdou, Hosoda, M., Bongue, D., Suzuki, T., Kudo, H., KwatoNjock, M.G. and Tokonami, S. (2019) Simultaneous Indoor Radon, Thoron and Thoron Progeny Measurements in Betare-Oya Gold Mining Areas, Eastern Cameroon. Radiation Protection Dosimetry, 185, 391-401.

[23] Sherafat, S., Mansour, S.N., Mosaferi, M., Aminisani, N., Yousefi, Z. and Maleki, S. (2019) First Indoor Radon Mapping and Assessment Excess Lifetime Cancer Risk in Iran. MethodsX, 6, 2205-2216. https://doi.org/10.1016/j.mex.2019.09.028

[24] ICRP Publication 103 (2018) The 2007 Recommendation International Commission on Radiological Protection, 2007.

[25] Elzain, A.-E.A. (2016) Measurements of Indoor Radon Levels and Dose Estimation and Lung Cancer Risk Determination for Workers in Health Centres of Some Towns 
in the Sudan. American Journal of Modern Physics, 5, 51-57.

https://doi.org/10.11648/j.ajmp.20160504.12

[26] BeyalaAteba, J.F., OwonoAteba, P., Ben-Bolie, G.H., EkobenaFouda, H., EleAbiama, P., Abega, C.R. and Mvondo, S. (2011) Determination of Uranium in Rocks and Soil of South Cameroon by Gamma Spectrometry. Radioisotopes, 60, 10.

https://doi.org/10.3769/radioisotopes.60.399

[27] EleAbiama, P., OwonoAteba, P., Ben-Bolie, G.H., EkobenaFouda, H.P. and El Khoukhi, T. (2010) High Background Radiation Investigated by Gamma Spectrometry of the Soil in the Southwestern Region of Cameroon. Journal of Environmental Radioactivity, 101, 739-743. https://doi.org/10.1016/j.jenvrad.2010.04.017

[28] International Atomic Energy Agency (2014) Radiation Protection and Safety of Radiation Dources: International Basic Safety Standards, General Safety Requirements Part 3, No. GSR Part 3. 